\title{
Factors Affecting Drug Compliance in Paediatric Asthma
}

\author{
Singh RK' ${ }^{1}$, Thapar RK ${ }^{2}$, Gupta RK $^{3}$, Abhijith $\mathbf{Y V}^{4}$
}

\begin{abstract}
Introduction: Childhood asthma is an immensely important chronic disease in children with increasing prevalence worldwide. Inhaled corticosteroids and bronchodilators are the key drugs in asthma therapy. Material and Methods: Compliance of childhood asthma was assessed at a tertiary care centre to find out the percentage of compliant Vs noncompliant patients and the reasons for the latter. If the patient had attended at least nine visits $(>75 \%)$ the previous year he was labelled compliant and those with less than six visits $(<50 \%)$ were put in the non-complaint group. Results: Of the 374 patients attending the asthma clinic, 60 were randomly selected for the study of which 53 finally participated. In this study the compliance was $47 \%$ and gender predilection did not affect compliance. The distance a patient had to commute to reach the hospital and the mother's education did not have any influence on the compliance. Older asthmatics exhibited better compliance in our study. Conclusion: Forty percent of our patients were compliant to regular use of prescribed medicine. Older age of the patients and care giver's awareness about asthma were the two factors which are statistically significant in compliance with drug therapy in asthma. Gender of the patient, academic qualification and distance from the hospital did not have a significant effect on compliance.
\end{abstract}

Key words: Paediatric asthma, compliance

\section{Introduction}

$B^{r}$ ronchial asthma is disease of respiratory system due to partial or complete obstruction of the airway. A large number of stimuli like allergens or infections may trigger the exacerbation. The median prevalence of asthma in Indian children is estimated to be $3.3 \%$. There is gradual increase in childhood asthma prevalence worldwide ${ }^{1}$. Inhaled corticosteroids are cornerstone of asthma management in children and adolescents. Inhaled corticosteroids control the airway inflammatory process, result in sustained asthma control, improve asthma symptoms and lung function and reduce frequency of flair ups $^{2}$. Inhaled beta-2 agonists are bronchodilators and are used for short term rescue therapy. Child's quality of life in asthma is directly proportional to the control of the disease. Uncontrolled asthma is associated with a reduced pulmonary function, poor performance
${ }^{1}$ Lt Col Rajesh Kumar Singh, MBBS. MD. Classified Specialist in Paediatrics, Command Hospital (Central Command) Lucknow, India, ${ }^{2}$ Col RK Thapar, MBBS, MD, Senior Advisor and Head of Department of Paediatrics and Neonatology, Command Hospital (Central Command) Lucknow, India, ${ }^{3}$ Brig RK Gupta, MBBS, MD, HoD Paediatrics, Armed Forces Medical College, Pune, India, ${ }^{4} \mathrm{Dr}$. Abhijith YV, MBBS, MD, Resident, Department of Paediatrics, $\mathrm{CH}$ (Central Command) Lucknow, India.

\section{Address for correspondence}

Lt Col RK Singh, Classified Specialist Paediatrics, Command Hospital (Central Command) Lucknow, Uttar Pradesh, India

Tel No; +919882624459

E-mail: rrarri@yahoo.co.in

\section{Acknowledgements: None \\ Funding: Nil \\ Conflict of Interest: None \\ Permission from IRB: Yes}

\section{How to cite}

Singh RK, Thapar RK, Gupta RK, Abhijith YV. Factors Affecting Drug Compliance in Paediatric Asthma. J Nepal Paediatr Soc 2017;37(1):31-35.

doi: http://dx.doi.org/10.3126/jnps.v37i1.17201

This work is licensed under a Creative Commons Attribution 3.0 License. 
in physical exercise, and severe clinical course ${ }^{3}$. Adherence to treatment is primary determinant to successful treatment not only in asthma but in all other chronic illnesses. Poor compliance compromises the clinical benefits. A WHO study states that only $50 \%$ of patients who suffer from chronic diseases adhere to treatment recommendations ${ }^{4}$. In an effort to improve the compliance we have to improve our knowledge of factors leading to poor compliance and address them. This may prove to be cost effective in long term disease control $^{5}$. It has been suggested that the term compliance be replaced by the term adherence which depicts the patient as an equal participant in his treatment rather than assuming a passive role $^{6}$.

Many studies have been undertaken to find the cause of noncompliance in chronic disease based on the socio demographic status of the patient. The aim of the present study was to find whether the compliance with asthma drugs has any significant relation with age, gender, distance of the patient's location from the hospital, academic qualification and basic understanding of asthma of the caregiver.

\section{Material and Methods}

Patients attending paediatric asthma clinic at Command Hospital Central Command Lucknow, tertiary care hospital of Armed Forces, India for a minimum of one year were randomly selected and their care giver was explained in detail about the study. It was emphasized that the enrolment in the study was voluntary, where confidentiality would be maintained and the interviews were recorded. The interviews were conducted during the OPD visits and the session lasted between 10 to 15 minutes. The recorded results were read aloud to the patient's care giver and were used for analysis subsequently.

The patients willing to participate in the study were classified according to standard protocol which included spirometry in children $>5$ years. The mild intermittent patients were not under regular follow up, hence the study included only persistent bronchial asthma cases which included mild, moderate and severe variety. Patients were divided into three groups as far as the severity of bronchial asthma was concerned as per standard definitions- mild persistent asthma, moderate persistent asthma and severe persistent asthma. The patient records were checked to find out whether they had attended their monthly scheduled visit to the asthma clinic or not. If the patient had attended at least 9 visits (> 75\%) the previous year he was labelled compliant and patients less than six visits $(<50 \%)$ were put in the non-complaint group. The patients attending 6-8 visits in previous year were excluded from the study.
The interviewer was blinded to the group to which a particular patient was assigned. Age of the patient, gender, whether located in urban or rural area, distance of the hospital from the patient's residence, level of care giver's academic education, number of acute episodes of asthma in the previous year, were the parameters which were assessed. A very important assessment made was whether the caregiver is educated about the disease in terms of awareness that asthma is a chronic disease with long duration of treatment, fear and awareness of adverse effects of inhaled corticosteroids, dislike of medications and the treatment duration and protocols being cumbersome.

The data was tabulated and the relevant statistical analysis was done using SPSS software. Permission for the study was obtained from the Institutional Review Board.

\section{Results}

Although population includes the mild intermittent cases, however these patients are not on regular follow up, hence were not included in the study. A total of 374 patients being managed by inhaled corticosteroids were registered at the asthma clinic in our centre. Out of these 374 patients, sixty were randomly approached, out of which 53 finally agreed to participate in the present study.

In the present study there were 36 males and 17 females with a M:F ratio of 2.1:1. Out of 53 patients only 02 were from a rural area, the rest being a part of urban population. The commonest age group was below five years of age (43\%) followed by $5-10$ yrs age group (40\%). Children above 10 years comprised $17 \%$ of the study group.

In this study majority of the patients resided within $5 \mathrm{~km}$ of the hospital (47\%) with only 09 patients had to come from a distance more than $10 \mathrm{~km}$ to seek medical attention (17\%). The majority of the caregivers were graduates $(60 \%)$ followed by 12 th standard pass $(25 \%)$ and below 10th standard (15\%). The patients who had mild persistent asthma was $94 \%$, followed by moderately persistent disease (6\%). No patient in our study had severe persistent asthma.

In the study 47 percent patients were compliant while the rest 53 percent were not compliant. In compliant group $28 \%$ of patients had exacerbation in previous one year compared to $32 \%$ patients in non-compliant group. This was statistically not significant $(p>0.05)$. The mean age of compliant vs non-compliant patient was 8.06 and 5.98 years and respectively, indicating that older patients had a better compliance $(p<0.005)$. When 
Table 1: Compaision of two groups for socio demographic factors and factors effecting compliance

\begin{tabular}{|c|c|c|c|c|}
\hline \multicolumn{2}{|c|}{ Factors } & \multirow{2}{*}{$\begin{array}{c}\text { Compliant } \\
25(47 \%)\end{array}$} & \multirow{2}{*}{$\begin{array}{c}\text { Noncompliant } \\
28(53 \%)\end{array}$} & \multirow{2}{*}{$\begin{array}{c}p \text {-value } \\
-\end{array}$} \\
\hline All & - & & & \\
\hline Male $(n=36)$ & - & 17 & 19 & \multirow{2}{*}{0.991} \\
\hline Female $(n=17)$ & - & 08 & 09 & \\
\hline Mean Age (yr) & - & 8.06 & 5.98 & 0.019 \\
\hline Rural & - & 2 & 0 & \multirow{2}{*}{0.127} \\
\hline Urban & - & 23 & 28 & \\
\hline \multirow{3}{*}{ Distance from hospital } & $0-5 \mathrm{~km}$ & 11 & 14 & \multirow{3}{*}{0.974} \\
\hline & $5-10 \mathrm{~km}$ & 09 & 10 & \\
\hline & $>10 \mathrm{~km}$ & 04 & 05 & \\
\hline \multirow{3}{*}{ Care giver's education } & $<10$ std & 05 & 03 & \multirow{3}{*}{0.220} \\
\hline & 10 std to graduation & 08 & 05 & \\
\hline & Graduation \& above & 12 & 20 & \\
\hline Acute exacerbation & - & 07 & 09 & 0.58 \\
\hline Fear of adverse drug reaction & - & 02 & 10 & 0.016 \\
\hline $\begin{array}{l}\text { Awareness of } \\
\text { chronicity of asthma } \\
\& \text { adverse drug effects }\end{array}$ & - & 20 & 8 & $<0.001$ \\
\hline
\end{tabular}

Table 2: The severity of asthma and its relation with age and compliance

\begin{tabular}{lccc}
\hline & Mild Persistent & Moderate persistent & Severe Persistent \\
\hline Less than 5 yr $(n=23)$ & 23 & 0 & 0 \\
\hline Between 5 \&10 yr $(n=21)$ & 19 & 02 & 0 \\
\hline More than 10 yr $(n=09)$ & 09 & 0 & 0 \\
\hline Compliant $(n=25)$ & 25 & 0 & 0 \\
\hline Non-compliant $(n=28)$ & 27 & 01 & 0 \\
\hline
\end{tabular}

patient's care giver in the compliant and non-compliant group was assessed for the understanding the chronic nature of asthma (including awareness of chronic nature of ailment and adverse effects of drugs) it was found that the compliant group had significantly more information about the disease as compared to the non-compliant group $(p<0.001)$

There was no significant correlation between the compliant and non-compliant patient as far as the gender; male vs female, location in urban or rural areas, distance from the hospital $(p=0.995)$ or academic qualification of the care giver $(p=0.220)$ was concerned.

\section{Discussion}

Compliance is understood as "patient's behaviours (in terms of taking medication, following diets, or executing life style changes) coinciding with healthcare providers' recommendations for health and medical

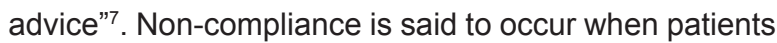
deviate from the prescribed instructions given by a healthcare professional. The objective of any medical therapy is to achieve certain desired outcomes. The result however depends largely on patient related factors and despite the efforts of the healthcare professionals, the desired outcomes might not be achieved if the patients are non-compliant. This is very pertinent in management of illnesses with long term treatment when compared to a short-term therapy in which the quoted compliance rate is between 70 percent and 80 percent to that of 20-30 percent of the former ${ }^{7}$. Studies have been done in other countries, to evaluate the impact and extent of therapeutic non-compliance in different diseases and different patient populations and it was found the compliance generally ranged between 40 percent and 50 percent ${ }^{8,9,10,11,12}$.

Drug compliance has been measured by various methodologies. Cochrane et al measured noncompliance by self-reporting, which though easy to do may not be entirely accurate and lead to an inflated percentage of compliance ${ }^{8}$. Use of standard questionnaires and counting the leftover tablets are other used methods ${ }^{13,14}$ In asthmatics use of electronic diary to record their symptom and self-measurement of lung function with a peak flow meter at home have also been suggested ${ }^{15,16}$ which may again be inaccurate due to clerical entry errors, mistimed entries, and deliberate wrong entries to 
please the clinician ${ }^{16,17}$. Weighing canisters of inhaler and pill counting is a more objective means of assessment but one can never be sure whether the drug has been actually used by the patient or not ${ }^{6}$. Drug levels can be monitored giving an accurate result but is prohibitively expensive in a developing country ${ }^{17}$. Three studies dealing with compliance in adult asthmatics done in Egypt, Sweden and USA have used questionnaires to decide the patient compliance ${ }^{5,18,19}$. A scale known as modified Morirsky scale which scored the, 'yes' and 'no' answers to determine compliance was also used 5 . The present study was in paediatric asthmatics and the children were understandably not able to give details of drug administered. Questionnaire to the mother was also not a viable option as it would have a patient bias. In this study once monthly OPD attendance was used as a surrogate marker of compliance.

Role of treatment compliance in management of asthma cannot be understated ${ }^{20}$. It has been found that the regular inhaled corticosteroids use can reduce asthma hospitalizations by $80 \%$. For every canister of inhaled corticosteroid use, the mortality in asthma almost goes down by 21 percent ${ }^{21}$. For inhaled corticosteroids to be effective, they have to be used in a proper manner. A less optimal technique results in decreased drug delivery and reduced efficacy ${ }^{22}$. Patient education, pulmonary function monitoring, environmental control and pharmacotherapy are the four mainstays of asthma management ${ }^{23}$.

In present study the male to female ratio was 2.1:1 while in other studies females were more with a 1.9:15. This could be due to a random selection of patients. In this study the compliance was 47 percent compared to the $49 \%$ and $53 \%$ in study be Nizar Rifat et al and Malou Lindberg et $\mathrm{al}^{5,18}$. The results did not differ much from the patients in both developing and developed countries. This observation reinforces the fact that compliance even in paediatric asthma like in other chronic illnesses and elsewhere in the world is a result of complex interplay between psychological, social and medical issues. Socioeconomic status and level of education markedly influences the way in which patients takes his treatment ${ }^{19}$. While Malou Lindberg et al found that females were more compliant than males but we did not find any gender predilection affecting compliance in this study ${ }^{18}$. Results similar to this study were reported by Rifat et al and Clarke et al $\left.\right|^{5,19}$. In this study the distance a patient had to commute to reach the hospital did not have an effect on the compliance.
Higher age of asthmatics correlated with better compliance in this study which is in concordance with all the above mentioned studies. These studies attributed the above mentioned finding to the fact that with increasing age an individual adjusts to its illness and accepts it as a part of his/her life situation. Some studies have found contrasting results stating that with increasing age a person dissociates himself with the prescribed drugs ${ }^{10}$. While the other studies were done in adult population ours was a paediatric study. It is suggested that the better compliance in elder children could be due to the fact that they were more expressive of their symptoms. Mother's academic education did not have any influence on the compliance of patient in this study, which is also brought out in other studies ${ }^{5,18}$. Di Metteo stated that even patients with high educational qualifications may not comprehend the benefits and necessity of adhering to a treatment ${ }^{24}$. One study did find that having a higher education benefitted compliance in patients of asthma ${ }^{19}$. Lesser number of compliant patients in our study had acute exacerbations compared to the non-compliant group. The above mentioned statistics could not be compared as this aspect has not been studied in paediatric asthma previously.

Being educated about various aspects of asthma such as understanding the requirement of long term and possibly a cumbersome treatment and being aware of the side effects of the drugs was noted in the compliant patient group which was in concordance with other studies $^{5,18,19}$. This was attributed to the fact that asthma education significantly increases the comprehension of medications and active participation of patients in treatment ${ }^{25}$. Making sure patients understand the drug dosing regimen could also improve compliance. It is stated that patients are by and large passive about the treatment and need education about the disease, encouragement to ask questions and overall listening and appreciating the patients' opinion about the disease.

\section{Conclusion}

The present study used scheduled OPD attendance to look for compliance as opposed to questionnaire or calculation of left over drug method. It was seen that 47 percent of our patients were compliant which was comparable to those in other parts of the world. Older age of the patients and awareness about asthma are the two factors which are statistically significant in compliance with drug therapy in asthma. Gender of the patient, academic qualification and distance from the hospital did not have a significant affect on compliance. 


\section{References}

1. Pal R Barua A. Prevalence of childhood bronchial asthma in India. Ann Trop Med Public Health 2008;1:73-5.

2. The Childhood Asthma Management Program Research Group. Long-term effects of budesonide or nedocromil in children with asthma. New Engl $J$ Med 2000;343:1054-63.

3. Lang A, Mowinckel P, Sachs-Olsen C. Asthma severity in childhood, untangling clinical phenotypes. PediatrAllergImmnol 2010;21:945-53.

4. World Health Organization, Adherence to long-term therapies: Evidence for action, 2003.

5. Rifaat N, Abdel-Hady E, Hasan AA. The golden factor in adherence to inhaled corticosteroid in asthma patients. Egypt J Chest Dis Tuberc 2013;62:371-76.

6. Steiner JF, Earnest MA. The language of medicationtaking.Ann Intern Med 2000;132:926-30.

7. Jin J, Sklar GE, Oh VMS, Li SC. Factors affecting therapeutic compliance: A review from the patient's perspective. TherClin Risk Manage 2008;4:269-86.

8. Cochrane GM. Compliance and outcome in patients with asthma. Drugs 1996;52:S12-19.

9. Sackett DL, Snow JC. The magnitude of compliance and non compliance. In: Haynes NRB, Taylor DW, Sackett DL, eds. Compliance in Health Care. Baltimore: John Hopkins University Press; 1979. p 11-22.

10. Deenen T, Clip EC. Coping with asthma. Resp Med 1993; 87:S67-70

11. Kjellgren K. Antihypertensive medication in clinical practice: aspects of patient adherence to treatment. Linköping :Univ, 1998 - 74 s.

12. Hansson Scherman M. Refusing to be ill. Alongitudinal study of patients relationship with their asthma/ allergy. Medical Dissertations. Gothenberg University, 1995.
13. Haynes RB, Taylor DW, Sackett DL, Gibson ES, Bernholtz CD, Mukherjee J. Can simple clinical measures detect patient noncompliance? Hypertension 1980;2:757-64

14. Morisky EE, Green LW, Levine DM. Concurrent and predictive validity of a self-reported measure of medication adherence. Med Care 1986;24:67-74.

15. Chowienczyk PJ, Lawson CP, Morris J, Kermani A, Cochrane GM. Electronic diary card to record physiological measurements. Lancet 1992;39:251.

16. Hyland ME, Kenyon CAP, Allen R, Howarth P. Diary keeping in asthma: comparison of the written and electronic methods. Br Med J 1993;306:487-9.

17. Cochrane GM. Compliance in asthma: a European perspective. Eur Respir J 1995;5:116-9.

18. Clark $\mathrm{N}$, Jones $\mathrm{P}$, Keller S. Patient factors and compliance with asthma therapy. Resp Med 1999;93:856-62.

19. Baiardini I, Braido F, Giardini A, Majani G, Cacciola C, Rogaku A et al. Adherence to treatment. J Invest Aller Clin Immunol 2006;16:218-23.

20. Suissa S, Ernst P, Benayoun S, Baltzan M, Cai B. Low-dose inhaled corticosteroids and the prevention of death from asthma. N Engl J Med 2000;343;332-36.

21. Khassawneh BY, Al-Ali MK, Alzoubi KH, Batarseh MZ, Al-Safi SA, Sharara AM et al. Handling of inhaler devices in actual pulmonary practice: Metereddose inhaler versus dry powder inhalers. Resp Care 2008;53:324-8

22. Indian guidelines of bronchial asthma in adults. J Assoc Physicians India. 2002; 50: 461-501.

23. DiMatteo MR. Patient adherence to pharmacotherapy: the importance of effective communication. Formulary 1995;30:596-98.

24. Rubin RR. Adherence to pharmacologic therapy in patients with type 2 diabetes mellitus. Am J Med 2005;118:27s-34s. 